\title{
Return-to-work outcomes in cancer survivors
}

\author{
Richard Crevenna ${ }^{1}$
}

Received: 12 June 2017 / Accepted: 10 July 2017 / Published online: 18 July 2017

(C) Springer-Verlag GmbH Germany 2017

Return to work seems to be a relevant and important issue for cancer patients [1-3]. About $60 \%$ of patients are able to work following a cancer diagnosis, and multidisciplinary programs have been shown to help cancer survivors to return to work [1-3].

In Germany, cancer patients have the right to participate in medical rehabilitation, depending on rehabilitation criteria, including need and the patient's prognosis. In this setting, occupation-oriented rehabilitation concepts for individuals with work-related problems are emphasized and the outcomes in the different phases of the return-to-work process are of high interest $[1,3]$. In their longitudinal multicentre study, "Outcomes across the return to work process in prostate cancer survivors attending a rehabilitation measure - results from a prospective study", Anneke Ullrich and colleagues analysed the return-to-work outcomes among prostate cancer survivors in different phases of the return-to-work process, which can be conceptualized as a multiphase construct based on a conceptual framework of occupational reintegration by Wasiak and colleagues [1,4]. The authors were able to show that most prostate cancer survivors have positive expectations regarding future working life in the 'off-work' phase and show favourable outcomes regarding their occupational reintegration (at 12-month follow-up). Furthermore, they were able to show that prostate cancer survivors with low socio-economic status are more often negatively affected [1]. Therefore, the authors emphasize that the important question of social

Richard Crevenna

richard.crevenna@meduniwien.ac.at

1 Department of Physical Medicine, Rehabilitation and Occupational Medicine, Medical University of Vienna, Waehringer Guertel 18-20, 1090 Vienna, Austria inequality should receive more and special attention in the setting of rehabilitation and work reintegration [1].

In their review "Exploration of return-to-work interventions for breast cancer patients: a scoping review", Bilodeau and colleagues indicate that it is important to define the returnto-work concept in order to develop appropriate multicomponent interventions based on current evidence, and explain survivorship care, including management of late symptoms that persist over time to facilitate return to work and job retention to be an important issue [5].

In my own country (Austria), cancer rehabilitation, with the goal to improve functional status, quality of life, and (social) participation, is also an important issue in the management of cancer patients. At the Comprehensive Cancer Centre (CCC) of the Medical University of Vienna (General Hospital of Vienna, Austria), we have a so-called CCC-platform for Side effectsManagement, Supportive Care \& Rehabilitation (CCCSMSCR) which is able to help patients to handle various barriers such as functional deficits, symptoms, and emotional distress [6]. Furthermore, this CCC-platform aims "to increase knowledge", "to inform and to network" and "to improve quality of treatment and care" at the moment especially including aspects of sports, workability, employment and return to work [7, 8]. So - besides other very important aspects of care and rehabilitation-workability, employment and return to work are very important and "modern" issues. This, especially due to the fact that a new law, as of the 1st of July 2017, in Austria, has been implemented. The so-called Wiedereingliederungsteilzeitgesetz - a law with the intention to help to integrate disabled people - for the first time will enable cancer survivors to return to work earlier. This will lead to a new and very challenging situation for all "players" in Austrian cancer survivorship care, and people planning rehabilitation and return-to-work concepts. A few months ago, the field of Occupational Medicine has been integrated into the former Department of Physical Medicine and Rehabilitation Medicine 
(part of the $\mathrm{CCC}$, coordinating the "CCC-platform for Side effects-Management, Supportive Care \& Rehabilitation") of the Medical University of Vienna, Austria. In our opinion, this new structure with a new Department of Physical Medicine, Rehabilitation and Occupational Medicine as part of the CCC, will help to coordinate rehabilitation and return to work for cancer survivors of our centre. Our interdisciplinary working group will report about this law's effects on cancer survivor's rehabilitation and return to work. Furthermore-for us and all other researchers examining this topic - it would be important to get in touch with other research groups (like Ullrich and colleagues, Bilodeau and colleagues) and build a network to conduct international research on factors affecting rehabilitation and work reintegration to improve the return-to-work process for cancer patients all over the world. Return to work seems to be a very important issue for many cancer patients. As many survivors are able and willing to work following a cancer diagnosis, future research should focus on rehabilitation and work reintegration concepts.

\section{Compliance with ethical standards}

Conflict of interest The author declares that he has no conflict of interest.

\section{References}

1. Ullrich A, Rath HM, Otto U, Kerschgens C, Raida M, HagenAukamp C, Bergelt C. Outcomes across the return-to-work process in prostate cancer survivors attending a rehabilitation measure - results from a prospective study. Support Care Cancer 2017 XXX

2. de Boer AG, Taskila T, Tamminga SJ et al (2011) Interventions to enhance return-to-work for cancer patients. Cochrane Database Syst Rev 16:CD007569

3. Hellbom M, Bergelt C, Bergenmar M et al (2011) Cancer rehabilitation: a Nordic and European perspective. Acta Oncol 50:179-186

4. Wasiak R, Young AE, Roessler RT et al (2007) Measuring return to work. J Occup Rehabil 17:766-781

5. Bilodeau K, Tremblay D, Durand MJ. Exploration of return-to-work interventions for breast cancer patients: a scoping review. Support Care Cancer 2017 Jun;25(6):1993-2007. doi: 10.1007/s00520-0163526-2. Epub 2017 Jan 4

6. Crevenna R. Crevenna $R$. Cancer Rehabilitation and palliative care - two important parts of comprehensive cancer care. Support Care Cancer 2015 Dec;23(12):3407-3408. doi: 10.1007/s00520015-2977-1. Epub 2015 Oct 6

7. Keilani M, Hasenoehrl T, Neubauer M, Crevenna R. Resistance exercise and secondary lymphedema in breast cancer survivors - a systematic review. Support Care Cancer 2016 Apr;24(4):1907-1916. doi: 10.1007/s00520-015-3068-z. Epub 2015 Dec 30

8. Neubauer M, Schoberwalter D, Cenik F, Keilani M, Crevenna R. Lymphedema and employability - review and results of a survey of Austrian experts. Wien Klin Wochenschr 2017 Mar;129(5-6):186191. doi: 10.1007/s00508-017-1167-1. Epub 2017 Jan 26 